\title{
DIAGNÓSTICO AMBIENTAL PEDOLÓGICO DA BACIA HIDROGRÁFICA DO RIO PARAIBUNA A PARTIR DO PROJETO RADAMBRASIL
}

\section{Anne Caroline Barbosa de Carvalho ${ }^{1}$}

\section{Geraldo César Rocha²}

\section{Ricardo Tavares Zaidan ${ }^{3}$}

RESUMO: O presente trabalho consiste na elaboração de um inventário das informações pedológicas presentes na Bacia Hidrográfica do Rio Paraibuna, localizada nos estados de Minas Gerais e Rio de Janeiro. O levantamento das classes de solo presentes na bacia teve como base o Projeto RADAMBRASIL (1983), e a atualização dessas classes foi realizada de acordo com Sistema Brasileiro de Classificação de Solos (EMBRAPA, 1999). Posteriormente, tais informações foram inseridas em um Sistema de Informações Geográficas o que possibilitou a produção de seis mapas: Classe de Solos, Cor, Fertilidade Química, Horizonte Diagnóstico Superficial (A), Textura e Relevo. Esse trabalho é parte integrante de um projeto mais abrangente denominado Diagnóstico Ambiental da Bacia Hidrográfica do Rio Paraibuna.

PALAVRAS CHAVE: Bacia Hidrográfica, Pedologia, Rio Paraibuna, Sistema de Informações Geográficas.

\section{INTRODUÇÃO}

A utilização que o homem tem feito dos recursos naturais nem sempre ocorreu considerando suas características e as capacidades de recuperação dos mesmos. Aliás,

\footnotetext{
${ }^{1}$ Geógrafa/Mestranda em Ecologia/ICB/UFJF. Email: carvalhoanne@hotmail.com

${ }^{2}$ Professor Associado/Departamento de Geociências/ICH/UFJF. Email: geraldo.rocha@ufjf.edu.com.br

${ }^{3}$ Professor Adjunto/Departamento de Geociências/ICH/UFJF. Email: ricardo.zaidan@ufjf.edu.com.br
} 
só mais recentemente ele passou a preocupar-se com os problemas ambientais. Os problemas ambientais graves, com reflexos sobre o próprio homem, levaram-no a procurar compreender melhor os fenômenos naturais e a entender que deve agir como parte integrante do sistema natural (MOTA, 1997).

Portanto, deve-se buscar a compreensão da complexidade envolvida no funcionamento dos diferentes mecanismos e processos que atuam nos sistemas naturais além da intensidade e da dinâmica das intervenções humanas.

A bacia hidrográfica tem sido usada como unidade de estudos ambientais por ser uma importante unidade espacial utilizada para gerenciar atividades de uso e de conservação dos recursos naturais, principalmente nas situações atuais de grande pressão sobre o ambiente.

A escolha da Bacia Hidrográfica do Rio Paraibuna (BHRP) como foco de estudo para este trabalho, ocorreu por ser um sistema localizado em uma importante área do país e por sustentar diversas atividades econômicas. E como muitas vezes esse florescimento econômico tem ocorrido desvinculado das questões ambientais, com ausência de planejamento adequado no uso e ocupação do solo, aliado as políticas inadequadas, permitindo a ocorrência crescente de perturbações com reflexos negativos, dos quais muitos são irreversíveis, a necessidade de focar estudos nesta unidade, direcionando as ações antrópicas para um planejamento adequado, se faz amplamente necessária.

Este estudo faz parte das ações para a realização de um projeto de pesquisa mais abrangente que está sendo desenvolvido pelo LGA - Laboratório de Geoprocessamento Aplicado do DEGEO/UFJF em parceria com o GEOPED - Laboratório de Geologia e Pedologia DEGEO/UFJF, cuja temática é o Diagnóstico Ambiental da Bacia Hidrográfica do Rio Paraibuna.

A realização de um diagnóstico envolve uma série de procedimentos metodológicos, visando à obtenção de um conjunto de dados que subsidiem a análise integrada e a produção de informações. São etapas dessa fase a obtenção de dados de entrada e a análise integrada, para que posteriormente possam ser elaborados indicadores como suporte à tomada de decisão. Os dados de entrada são geralmente agrupados por temas para melhor compreensão e interpretação. Os temas escolhidos 
variam segundo as diretrizes e os objetivos específicos em cada caso, contabilizando aspectos físicos, biológicos, econômicos, sociais e culturais (LAURENTIS et al, 2009).

Para tanto, tem-se nos Sistemas de Informações Geográficas (SIGs), uma importante ferramenta, que possibilita o processamento dessas informações multidisciplinares de forma integrada, além de permitir o relacionamento dos dados com sua representação espaço-temporal.

O presente trabalho tem como principal proposta a análise pedológica da área de estudo a partir do levantamento das classes de solos presentes no Projeto RADAMBRASIL (1983), com a atualização dessas classes de acordo com Sistema Brasileiro de Classificação de Solos (EMBRAPA, 1999).

\section{MATERIAL E MÉTODOS}

Área de estudo - localiza-se na região sudeste do país, com terras drenadas tanto no estado de Minas Gerais quanto no estado do Rio de Janeiro. Possui uma área de 8.593 km² (CASTRO, 2009), e grande parte desta área está inserida em escala regional, na Zona da Mata Mineira, e possui como principais afluentes o Rio Preto, o Rio do Peixe e o Rio Cágado.

O material utilizado para o reconhecimento da área de estudo foi o Projeto RADAMBRASIL (1983). Trabalhou-se com o levantamento pedológico pautado no Projeto RADAMBRASIL, Volume 32, páginas 385 a 552 e seu respectivo mapa em escala 1:1.000.000, Folhas SF.23/24 Rio de Janeiro/Vitória.

Posteriormente, no mapa do RADAMBRASIL foi feito um recorte com os limites da bacia. O georreferenciamento e a delimitação da bacia, e suas respectivas características foram armazenadas em ambiente SIG segundo procedimentos adotados por CASTRO (2009); tal método foi útil por possibilitar a confecção e a manipulação dos mapas da bacia com as devidas classes de solos.

Após este procedimento, o mapa do RADAMBRASIL foi digitalizado e suas informações foram armazenadas em um banco de dados. A digitalização foi realizada a 
partir da criação de polígonos contendo os limites de cada nível. As informações dos níveis foram obtidas a partir da legenda do próprio mapa do RADAMBRASIL, onde foram se somando à medida que novos níveis hierárquicos foram estabelecidos.

Dessa forma, no primeiro nível, por exemplo, foram colocadas informações das classes de cada solo da BHRP; estes dados foram complementados pelas informações das cores dos solos descritas no segundo nível, e estas complementadas pelas informações de fertilidade química descritas no terceiro nível e assim por diante, até o sexto nível.

De acordo com Xavier da Silva (2001), o banco de dados é uma disposição conjugada de variáveis segundo suas ocorrências em unidades territoriais. As variáveis escolhidas são dispostas em um determinado número de linhas, e as unidades territoriais de integração dos dados são colocadas em um determinado número de colunas. $\mathrm{O}$ encontro entre linhas e colunas contém as instâncias de ocorrência, que são os dados a serem analisados.

Além de demonstrar a disposição dos dados em uma tabela, o banco de dados mesmo sendo uma primeira expressão da natureza dos sistemas geográficos de informação, permite outras operações relevantes sobre os dados ambientais. Torna-se possível toda uma série de manipulações transformadoras dos dados, sendo uma das mais diretas o agrupamento das unidades territoriais segundo classes de ocorrência verificadas, gerando uma classificação destas mesmas.

Segundo a Embrapa (1999), nível categórico de um sistema de classificação de solos é um conjunto de classes definidas num mesmo nível de generalização ou abstração e incluindo todos os solos que satisfizerem a essa definição. As características ou propriedades usadas para a definição de um nível categórico foram propriedades dos solos que podem ser identificadas no campo ou que podem ser inferidas de outras propriedades que são reconhecidas no campo ou a partir de conhecimentos da ciência do solo e de outras disciplinas correlatas. As características diferenciais para os níveis categóricos mais elevados da classificação de solos foram propriedades dos solos que resultam diretamente dos processos de gênese do solo porque estas propriedades apresentam um maior número de características acessórias. 
Pelo fato do Sistema Brasileiro de Classificação de Solos abranger outras características que não se mostraram de interesse para esse trabalho, utilizou-se as características dos solos adotada no RADAMBRASIL (1983).

Assim, os níveis hierárquicos escolhidos e em ordem crescente, foram: Classe de Solo, Cor, Fertilidade Química, Horizonte Diagnóstico Superficial, Textura e Relevo.

No 1ำnível ou Classe de Solo estão presentes os elementos pelos quais as classes são diferenciadas na aplicação do sistema de solos, isto é, atributos que distinguem as classes das demais de mesmo nível categórico. Constituem as características diferenciais da classe.

No $2^{\circ}$ nível estão presentes as diferentes cores encontradas para cada solo. A cor corresponde a uma das características morfológicas do solo e sofre influência preponderante de fatores tais como: matéria orgânica, compostos de ferro e o conteúdo de minerais claros. A determinação das cores é feita pela comparação de amostras de solo com tabelas, especialmente usadas para solos, dentre as quais pode ser citada a de Munsell.

O 3nível ou Fertilidade Química corresponde dentre outras características a atividade de argila, condição de saturação do complexo por bases ou por alumínio.

O 4º nível, ou Horizonte Diagnóstico Superficial $(A)$, representa um conceito de importância ambiental, pois é o horizonte mais superficial do solo, então sujeito mais diretamente aos impactos ambientais.

O 5ํำ nel, ou Textura, corresponde à composição granulométrica do solo e pode ser definido pela reunião de uma ou mais classes de textura, sendo importante na análise de processos erosivos.

O 6ํo nível é o relevo. A denominação utilizada para esse nível se refere geralmente, a lugares onde a série foi reconhecida e descrita pela primeira vez e possui como objetivo principal fornecer subsídios ao estabelecimento das limitações dos solos como suscetibilidade à erosão.

\section{RESULTADOS E DISCUSSÃO}


Após a digitalização dos níveis propostos, eles foram subdivididos em suas respectivas características as quais foram quantificadas (Tab. 1).

Porcentagem das Características dos Níveis Hierárquicos da Bacia Hidrográfica do Rio Paraibuna

\begin{tabular}{|c|c|c|c|c|c|}
\hline 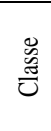 & $\begin{array}{l}\text { Argissolo } \\
\text { Cambissolo } \\
\text { Latossolo }\end{array}$ & $\begin{array}{r}4,74 \% \\
22,74 \% \\
72,49 \%\end{array}$ & 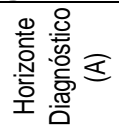 & $\begin{array}{l}\text { Húmico } \\
\text { Moderado } \\
\text { Proeminente a moderado }\end{array}$ & $\begin{array}{c}0,55 \% \\
92,26 \% \\
7,19 \%\end{array}$ \\
\hline ১̀ & $\begin{array}{l}\text { Vermelho } \\
\text { Sem cor } \\
\text { Vermelho-Amarelo }\end{array}$ & $\begin{array}{r}4,74 \% \\
22,74 \% \\
72,49 \%\end{array}$ & 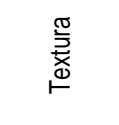 & $\begin{array}{l}\text { Argilosa } \\
\text { Argilosa a muito argilosa } \\
\text { Média a argilosa } \\
\text { Média a muito Argilosa }\end{array}$ & $\begin{array}{c}22,05 \% \\
50,44 \% \\
22,78 \% \\
4,73 \%\end{array}$ \\
\hline 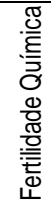 & \begin{tabular}{|l} 
Álico \\
Distrófico
\end{tabular} & $\begin{array}{l}73,75 \% \\
26,25 \%\end{array}$ & $\begin{array}{l}\stackrel{\rho}{\Phi} \\
\frac{d}{\Phi}\end{array}$ & $\begin{array}{l}\text { Montanhoso } \\
\text { Montanhoso e escarpado } \\
\text { Montanhoso e forte ondulado } \\
\text { Ondulado e forte ondulado }\end{array}$ & $\begin{array}{c}1,42 \% \\
17,13 \% \\
80,00 \% \\
1,45 \%\end{array}$ \\
\hline
\end{tabular}

Tabela 1. Porcentagem das características dos níveis hierárquicos adotados.

No primeiro nível foi constatada a presença de três classes (ordens) de solo: Argissolos, Latossolos e Cambissolos (Fig. 1). É possível observar o predomínio dos Latossolos ocupando mais de $72 \%$ da área da bacia.

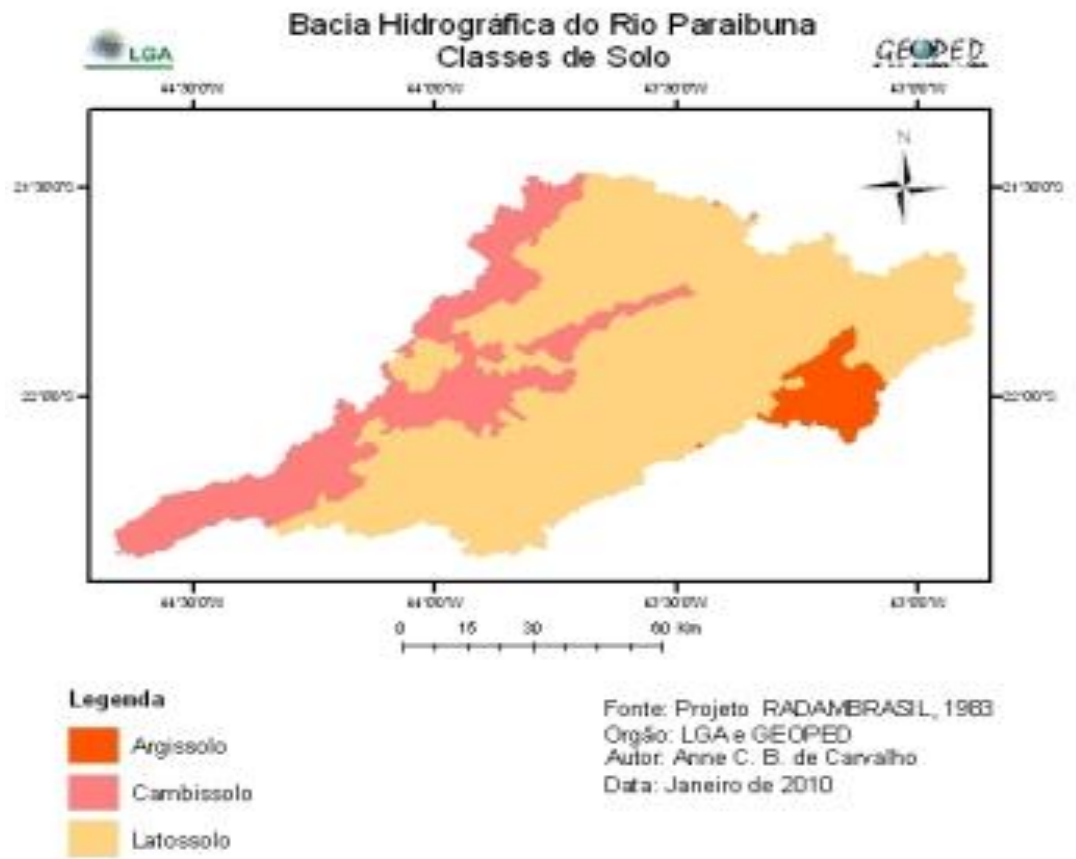

Figura 1. Mapa da BHRP segundo as classes de solo. 
Na hierarquização dos níveis de acordo com o RADAMBRASIL (1983), as cores vêm como segundo nível (Fig. 2). No nível de cores pode ser destacada a presença de solos vermelhos pela existência de Argissolos Vemelhos e solos vermelho-amarelo como nos Latossolos Vermelho-Amarelo e solos que não apresentam uma cor específica como pode ser verificado nos Cambissolos. A predominância é de solos com coloração vermelho-amarelo, ocupando $72,49 \%$ da área da bacia.

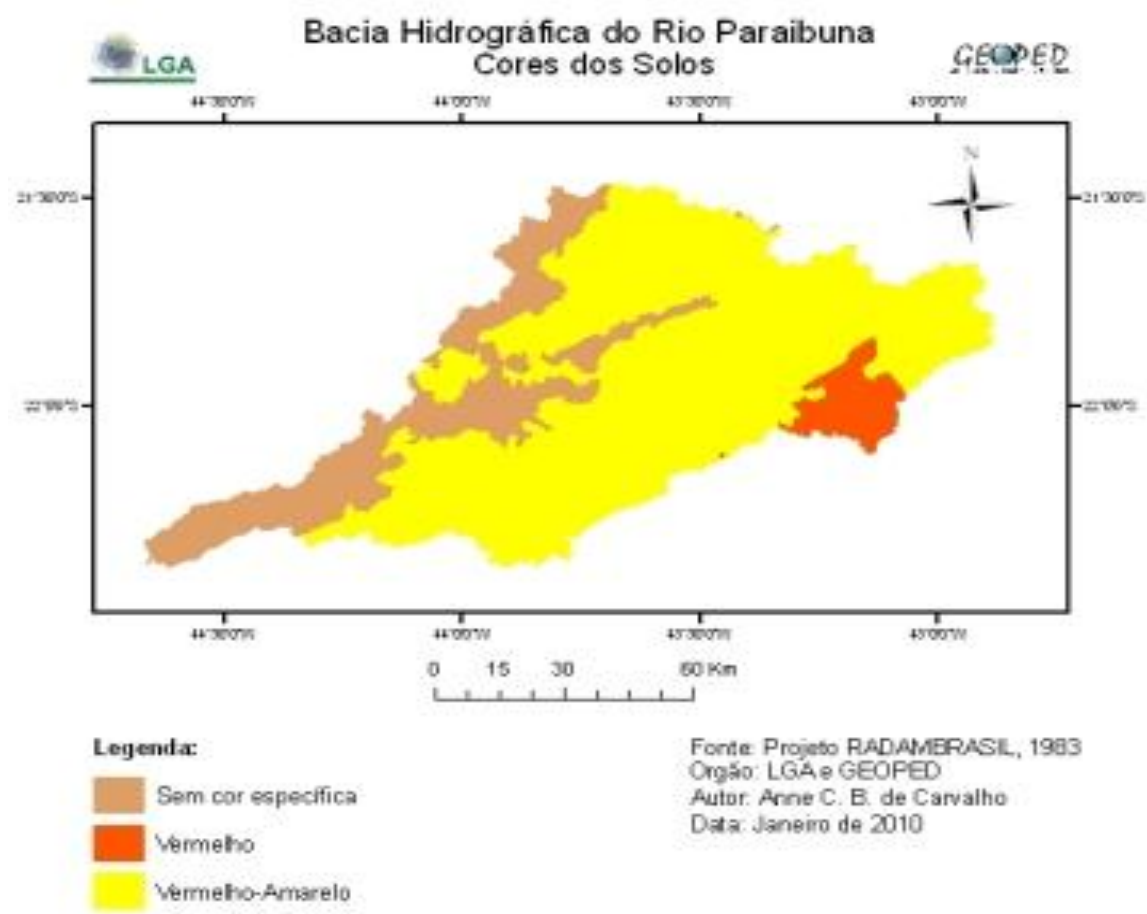

Figura 2. Mapa da BHRP segundo as cores dos solos.

Após esta classificação os solos foram novamente reagrupados de acordo com a fertilidade química. Dentro desse nível é possível observar que os solos presentes na área são pobres quimicamente, sejam álicos ou distróficos (Fig 3).

A denominação álico é empregada para designar saturação com alumínio igual ou superior a $50 \%$ e distrófico para os solos que apresentam saturação de bases baixa, ou seja, inferior a $50 \%$. Os solos álicos ocupam $73,75 \%$ enquanto os solos distróficos ocupam $26,25 \%$ da área. Não existem solos eutróficos na área. 

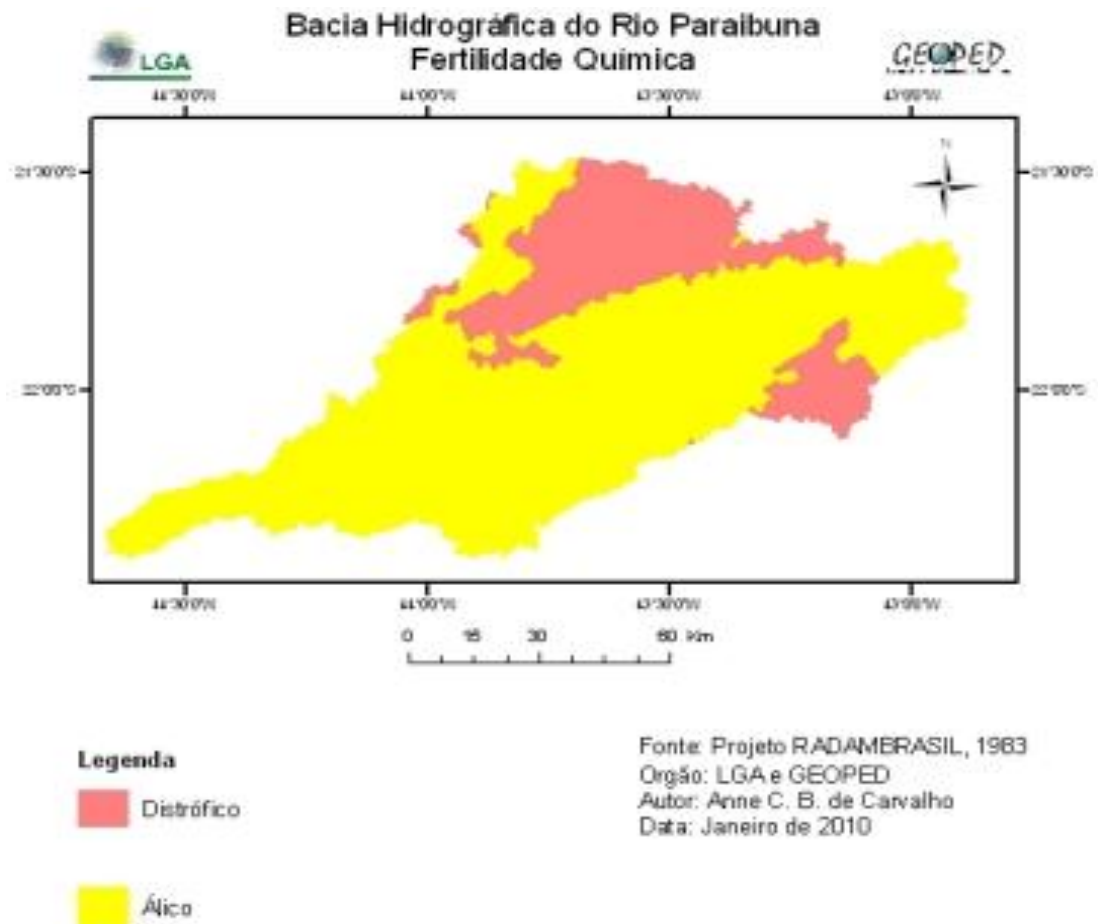

Fonte Projeto RADAMERASIL, 1983

Orgăo: $L Q A$ E GEOPED

Autor: Avine C. B. de Canalho

Data: Janeiro de 2010

Figura 3. Mapa da BHRP segundo a fertilidade química.

Posteriormente, os solos foram subdivididos em relação ao tipo de horizonte diagnóstico superficial (A). Nesse nível, aparecem os solos com horizontes Húmico, Moderado e Proeminente a Moderado (Fig. 4). Porém, são os solos com horizonte A Moderado que possuem maior representatividade, ocupando, 92,26\% da área de estudo, o que indica um potencial preocupante frente à erosão. 


\section{Periódica Eletrônica \\ FÓRUM AMBIENTAL DA ALTA PAULISTA}

Volume VI - Ano 2010

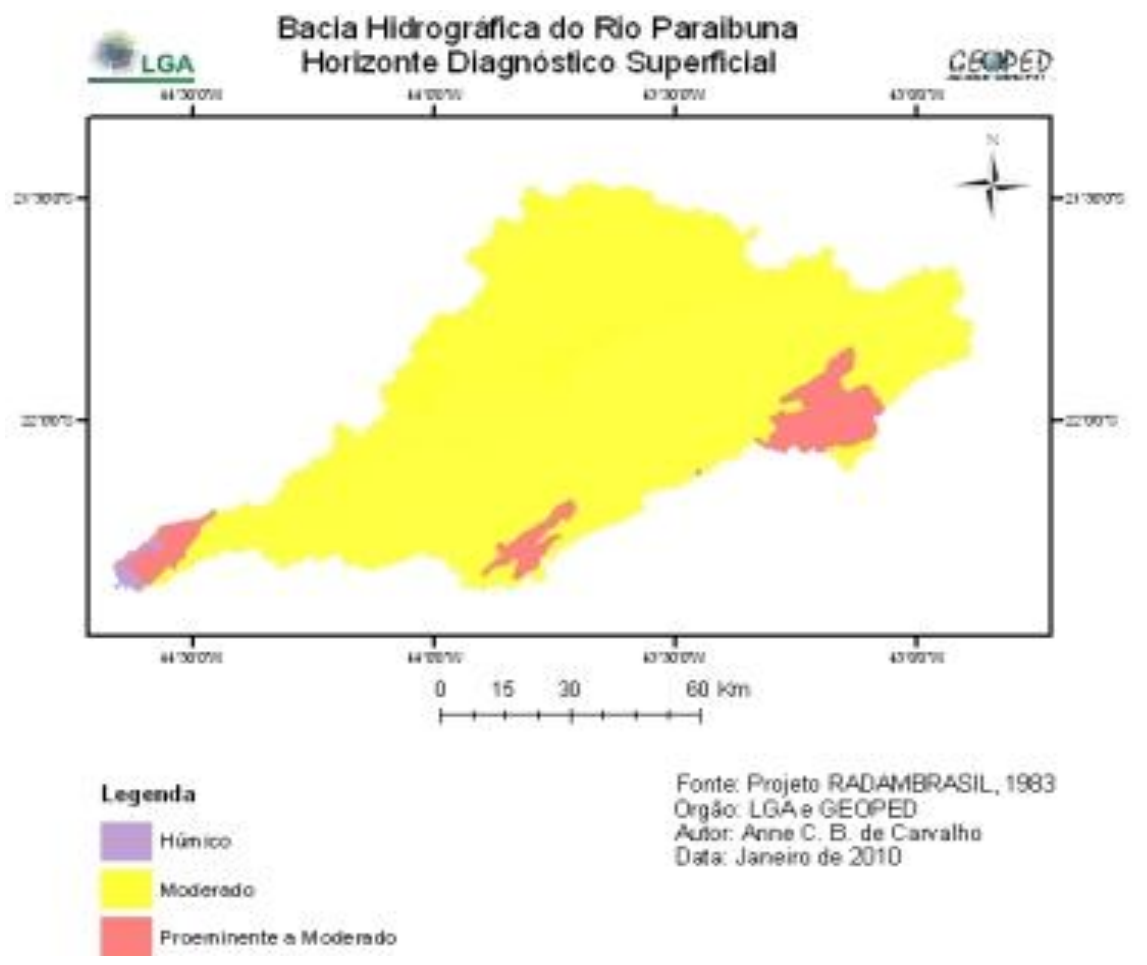

Figura 4. Mapa da BHRP segundo o horizonte diagnóstico superficial (A).

Após a classificação dos solos por horizonte superficial há novamente a subdivisão dos mesmos quanto à textura. Neste nível existem solos com textura Argilosa, Argilosa a Muito Argilosa, Média a Argilosa e Média a Muito Argilosa (Fig. 5). Os solos com textura Argilosa possuem em sua composição entre 35\% a $60 \%$ de argila. Já os solos com textura variando entre Argilosa a muito Argilosa possuem de $35 \%$ a $60 \%$ ou mais de argila. Os solos com textura Média a Argilosa possuem 15\% de areia e 35\% ou menos a $60 \%$ de argila. E os solos com textura variando entre Média a muito Argilosa possuem $15 \%$ de areia, menos de $35 \%$ de argila ou mais de $60 \%$ de argila. Na Bacia a predominância é de solos com textura variando entre Argilosa a muito Argilosa, estes ocupam mais de $50 \%$ da área. 


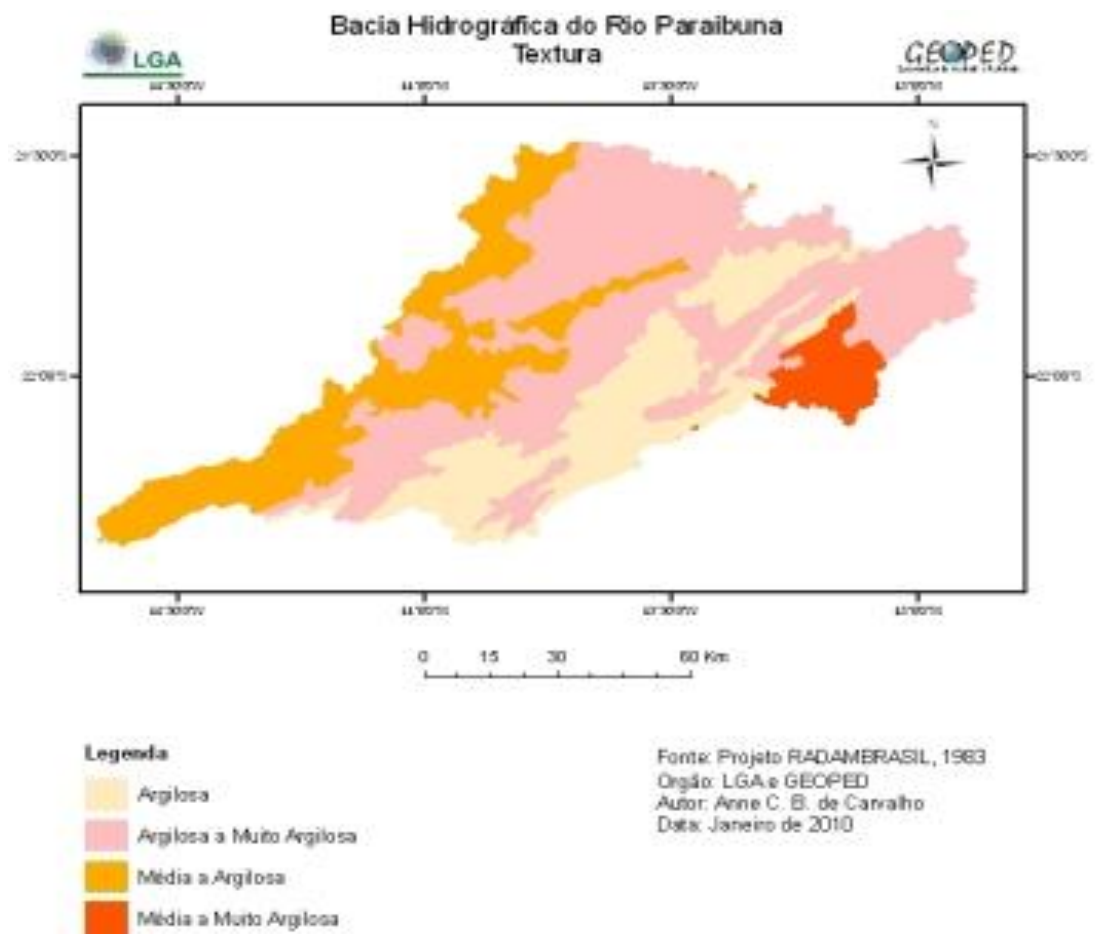

Figura 5. Mapa da BHRP segundo a textura do solo.

$\mathrm{Na}$ hierarquização final os solos foram subdivididos de acordo com o relevo. Neste nível são qualificadas as condições de declividade, comprimento de encostas e configuração superficial dos terrenos, que afetam as formas topográficas de áreas de ocorrência das unidades de solo (EMBRAPA, 1999).

Pode-se destacar o aparecimento de áreas com relevo Montanhoso, Montanhoso e Escarpado, Montanhoso e Forte Ondulado e Ondulado e Forte Ondulado (Fig. 6). No relevo Montanhoso estão presentes superfícies de formas acidentadas, usualmente constituídas por morros, montanhas, maciços montanhosos e alinhamentos montanhosos, apresentando desnivelamentos relativamente grandes e declives fortes ou muito fortes, predominantemente variáveis de 45 a 75\%. No relevo Montanhoso e Escarpado são encontradas áreas com as mesmas características do relevo Montanhoso além de formas abruptas, compreendendo superfícies íngrimes com declives muito fortes, usualmente ultrapassando 75\%. Já no relevo do tipo Montanhoso e Forte Ondulado estão presentes áreas com características do relevo montanhoso e superfícies com declividades variando entre 20 a 45\%. E por fim, no relevo Ondulado e Forte Ondulado estão presentes áreas com declividades moderadas, variando entre 8 a $20 \%$ além de superfícies com as mesmas características do relevo Forte Ondulado. 


\section{Periódica Eletrônica

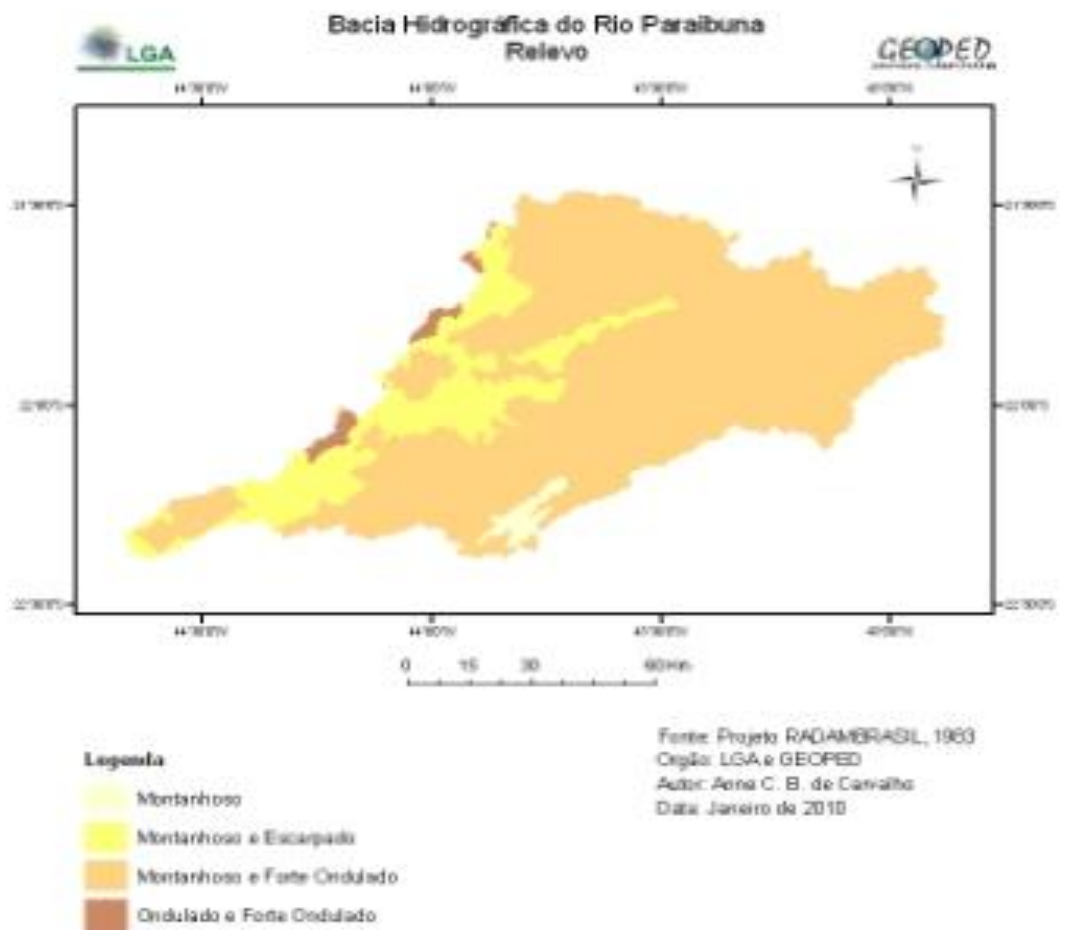

Figura 6. Mapa da BHRP segundo o relevo.

\section{CONCLUSÃO}

Predominam na Bacia Hidrográfica do Rio Paraibuna os solos do tipo Latossolo Vermelho-Amarelo e os Cambissolos.

De acordo com a distribuição por fertilidade química em toda a bacia, é possível perceber que os solos são pobres quimicamente, sejam álicos ou distróficos.

Quase toda a BHRP é constituída por solos com horizonte diagnóstico superficial do tipo moderado, o que indica um potencial preocupante frente à erosão.

$\mathrm{Na}$ BHRP a predominância é de solos com textura variando entre argilosa a muito argilosa, principalmente nas porções norte, leste e sudoeste.

O relevo predominante na BHRP é o montanhoso e forte ondulado. Abrange as porções norte, sul, sudoeste e leste o que demonstra que grande parte da bacia apresenta formas acidentadas com desnivelamentos relativamente grandes e declives fortes ou muito fortes com variações de $20 \%$ a $75 \%$. 
Os resultados, ainda que preliminares, dão base para a elaboração de planos conservacionistas de propriedades agrícolas, através da produção de cartas de distribuição de solos segundo aptidões ou limitações de uso. Para isso é possível, por exemplo, cruzar dados como: classe de solo, fertilidade química e relevo.

Os dados disponíveis também podem ser aplicados para o meio urbano na elaboração de cartas de suscetibilidade à erosão cruzando-se, por exemplo, os dados de classe de solo, textura e relevo.

Dessa forma, é possível perceber que a utilização do SIG para a confecção de mapas é importante por possibilitar futuras interpretações e cruzamentos das informações disponíveis, que poderão ser utilizadas para agilizar a sustentabilidade nas tomadas de decisão.

\section{REFERÊNCIAS}

BRASIL. Rio de Janeiro/Vitória. Brasília: Ministério das Minas e Energia - Secretaria Geral, v.32. 1983. (Projeto RADAMBRASIL - Levantamento de Recursos Naturais).

. Ministério das Minas e Energia. Projeto RADAMBRASIL, 1983. Folhas SF. 23/24 Rio de Janeiro/Vitória. Pedologia. Rio de Janeiro: DNPM, v. 32.

CÂMARA, G., DAVIS, C. Introdução à Ciência da Geoinformação. 2003. Disponível na Internet via www URL: http//www.dpi.inpe.br/gilberto/livro/introd/cap1-cartografia.pdf. Arquivo consultado em 2009.

CASTRO, T.G.S. Análise das características geomorfológicas da Bacia Hidrográfica do Rio Paraibuna - MG/RJ - A partir do Projeto RADAMBRASIL. (Monografia de Graduação em Bacharelado). Departamento de Geociências, UFJF, Juiz de Fora, 2009.

D’ALGE, J.C.L. Introdução à Ciência da Geoinformação. 2003. Disponível na Internet via www URL: http//www.dpi.inpe.br/gilberto/livro/introd/cap6-cartografia.pdf. Arquivo consultado em 2009.

EMBRAPA. Centro Nacional de Pesquisa de Solos (Rio de Janeiro, RJ). Sistema Brasileiro de Classificação de Solos. Brasília: Embrapa Produção de Informação; Rio de Janeiro: Embrapa Solos, 1999.

LAURENTIS, G.L., DEMANBORO, A.C., CONFORTI, T.B., ADAMI, S.F., BETTINI,S.C. Diagnóstico ambiental da bacia hidrográfica do Rio Atibaia, SP, utilizando ferramentas de geoprocessamento. Anais II Seminário de Recursos Hídricos da Bacia Hidrográfica do 
Paraíba do Sul: Recuperação de Áreas Degradadas, Serviços Ambientais e Sustentabilidade. Taubaté, 2009. IPABHi, p.89-96.

MENDOZA, E. Projeto RADAMBRASIL, 2008. Disponível na Internet via www URL: http://www.projeto.radam.nom.br/historico.html. Arquivo consultado em 2009.

MOTA, S. Introdução à Engenharia Ambiental. 1ed. São Paulo: ABES, 1997.

MUNSELL. Soil Color Charts. Baltimore, Munsell Color Comp., 1975. tab.

OLIVEIRA, A.A.B., Projeto RADAMBRASIL, 2008. Disponível na Internet via www URL: http://www.projeto.radam.nom.br/metodologia.html. Arquivo consultado em 2009.

ORLANDO, P.H.K. Produção do espaço e gestão hídrica na Bacia do Rio Paraibuna (MG/RJ): uma análise crítica. Tese/UNESP, São Paulo, 2006. (Doutorado).

REUNIÃO TÉCNICA DE LEVANTAMENTO DE SOLOS, 10., Rio de Janeiro, 1979. Súmula. Rio de Janeiro, Serviço Nacional de Levantamento e Conservação de Solos, 1979. 83p. (Série Miscelânia, 1).

RODRIGUES, C., ADAMI, S. Técnicas fundamentais para o estudo de bacias hidrográficas. In: VENTURI, L.A.B. (ORG). Praticando Geografia: técnicas de campo e laboratório. São Paulo: Oficina de Textos, 2005. p. 147-166.

SILVA, A.M., SCHULZ, H.E., CAMARGO, P.B. Erosão e Hidrossedimentologia em Bacias Hidrográficas. São Carlos: Rima, 2003.

SOCIEDADE BRASILEIRA DE CIÊNCIA DO SOLO. Comissão Permanente de Métodos de Trabalho de Campo. Manual de método de trabalho de campo. Rio de Janeiro: Divisão de Pedologia e Fertilidade do Solo, 1967.

VEIGA, T.C., SILVA, J.X. Geoprocessamento aplicado à identificação de áreas potenciais para atividades turísticas: o caso do município de Macaé - RJ. In: SILVA, J.X., ZAIDAN, R.T. (ORG). Geoprocessamento \& Análise Ambiental. Rio de Janeiro: Bertrand Brasil, 2004. p. 179- 215.

XAVIER-DA-SILVA, J. Geoprocessamento para Análise Ambiental. Rio de Janeiro: sn, 2001.

ZAIDAN, R.T. Riscos de Escorregamentos numa Bacia de Drenagem Urbana no Município de Juiz de Fora - MG. Tese/UFRJ, Rio de Janeiro, 2006. (Doutorado). 